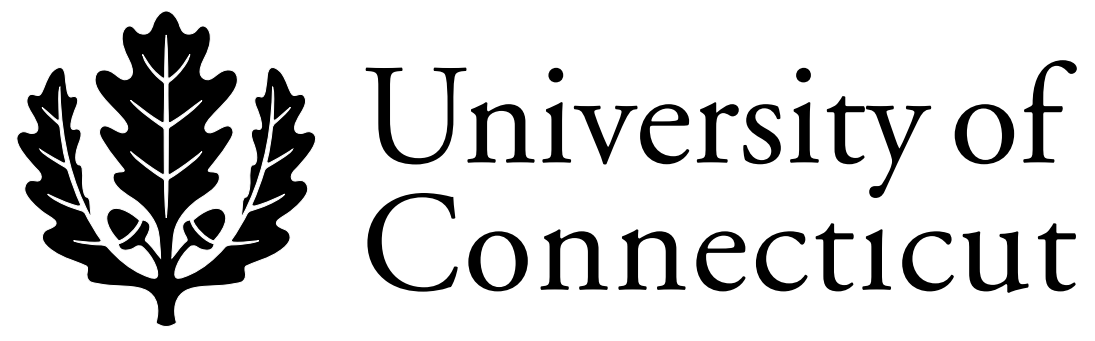

Department of Economics Working Paper Series

The Directional Distance Function and Measurement of SuperEfficiency: An Application to Airlines Data

Subhash C. Ray

University of Connecticut

Working Paper 2004-16

May 2004

341 Mansfield Road, Unit 1063

Storrs, CT 06269-1063

Phone: (860) 486-3022

Fax: (860) 486-4463

http://www.econ.uconn.edu/ 


\begin{abstract}
Lovell and Rouse (LR) have recently proposed a modification of the standard DEA model that overcomes the infeasibility problem often encountered in computing super-efficiency. In the LR procedure one appropriately scales up the observed input vector (scale down the output vector) of the relevant superefficient firm thereby usually creating its inefficient surrogate. An alternative procedure proposed in this paper uses the directional distance function introduced by Chambers, Chung, and Fre and the resulting Nerlove-Luenberger (NL) measure of super-efficiency. The fact that the directional distance function combines features of both an input-oriented and an output-oriented model, generally leads to a more complete ranking of the observations than either of the oriented models. An added advantage of this approach is that the NL super-efficiency measure is unique and does not depend on any arbitrary choice of a scaling parameter. A data set on international airlines from Coelli, Perelman, and Griffel-Tatje (2002) is utilized in an illustrative empirical application.
\end{abstract}




\section{THE DIRECTIONAL DISTANCE FUNCTION AND MEASUREMENTOF SUPER-EFFICIENCY: AN APPLICATION TO AIRLINES DATA}

Data Envelopment Analysis (DEA) provides an objective basis for ranking firms in an industry in order of their measured technical efficiency scores. This, however, is not possible for the sub-group of firms that lie on the graph of the technology and are all rated at 100\% technical efficiency. A procedure first proposed by Andersen and Petersen (1993) uses the super-efficiency measures of these efficient firms to resolve this problem. A firm is regarded as super-efficient if its DEA efficiency score exceeds $100 \%$ when measured against a production possibility set constructed from the input-output data of all other firms in the sample. While this modified DEA procedure is quite useful in most cases, the relevant linear programming problem for measuring the super-efficiency score may not have any feasible solution in certain situations. Chavas and Cox (1999) point out that Shephard (1970) made an input attainability assumption that ensures that all output bundles can be produced from the rescaling of any non-zero input bundle. Similarly, by the output attainability assumption, every input bundle is feasible in the production of any rescaled non-zero output bundle. The problem of feasibility arises in an output-oriented (input-oriented) super-efficiency model when an efficient input-output bundle fails to satisfy the input (output) attainability assumption with respect to the modified production possibility set. Several authors (e.g., Thrall (1996), Zhu (1996), Dula and Hickman (1997), Seiford and Zhu (1999), and Harker and Xue (2002)) have noted various necessary and sufficient conditions for infeasibility in super-efficiency DEA models. Lovell and Rouse (LR) (2003) have recently proposed a modification of the standard DEA model that overcomes the infeasibility problem. The essence of the LR procedure is to appropriately scale up the observed input vector (scale down the output vector) of the relevant super-efficient firm thereby usually creating its inefficient surrogate ${ }^{1}$. Because an inefficient firm plays no role in defining the frontier, it would not make any difference whatsoever if the firm with the revised input/output data is retained in the reference set. An alternative procedure proposed in this paper uses the directional distance function introduced by Chambers, Chung, and Färe (1996) and the resulting Nerlove-Luenberger (NL) measure of super-efficiency. The paper unfolds as follows. Section 2 describes the directional distance function and the associated NL efficiency measure. Section 3 presents the standard Debreu-Farrell super-efficiency model along with the NL super-efficiency model. Section 4 addresses the infeasibility problem that sometimes arises in a super-efficiency model and compares the LR approach with the one presented in this paper in solving the problem. A data set on international airlines from Coelli, Perelman, and Griffel-Tatje (2002) is utilized in an illustrative empirical application presented in section 5. The main conclusions are summarized in section 6 .

\section{The Directional Distance Function and Nerlove-Luenberger Efficiency}

Chambers, Chung, and Färe (1996) introduced the directional distance function based on Luenberger's benefit function to obtain a measure of technical efficiency reflecting the potential for increasing outputs

\footnotetext{
${ }^{1}$ As discussed below, in some cases with 0 values of individual outputs or inputs, even the surrogate remains efficient.
} 
while reducing inputs simultaneously. Consider some input-output bundle $\left(x^{0}, y^{0}\right)$ and a reference inputoutput bundle $\left(g^{x}, g^{y}\right)$. Then, with reference to some production possibility set, $T$, the directional distance function can be defined as:

$$
\stackrel{\nu}{D}\left(x^{0}, y^{0} ; g^{x}, g^{y}\right)=\max \beta:\left(x^{0}+\beta g^{x}, y^{0}+\beta g^{y}\right) \in T .
$$

Clearly, the directional distance function evaluated at any specific input-output bundle will depend on $\left(g^{x}, g^{y}\right)$ as well as on the reference technology. The bundle $\left(g^{x}, g^{y}\right)$ defines the direction along which the observed bundle, if it is an interior point, is projected on to the efficient frontier of the production possibility set. In (1) above, the bundle $\left(g^{x}, g^{y}\right)$ is chosen quite arbitrarily. As suggested by Chambers, Chung, and Färe, we may select $\left(-x^{0}, y^{0}\right)$ for $\left(g^{x}, g^{y}\right)$ and in that case the directional distance function becomes

$$
\breve{D}\left(x^{0}, y^{0}\right)=\max \beta:\left((1-\beta) x^{0},(1+\beta) y^{0}\right) \in T .
$$

In other words, we seek to increase the output and reduce the input simultaneously by the proportion $\beta$. For example, if $\beta$ equals $10 \%$, we expand all outputs by $10 \%$, while at the same time reducing all inputs by $10 \%$.

Under the standard assumptions of convexity and free disposability of inputs and outputs, the production possibility set constructed from a set of $N$ observed input-output bundles $\left(x^{j}, y^{j}\right)(j=1,2, \ldots, N)$ is

$$
T=\left\{(x, y): x \geq \sum_{1}^{N} \lambda_{j} x^{j} ; y \leq \sum_{1}^{N} \lambda_{j} y^{j} ; \sum_{1}^{N} \lambda_{j}=1 ; \lambda_{j} \geq 0 ;(j=1,2, \ldots, N)\right\} .
$$

The VRS DEA formulation for the directional distance function for this production possibility set is:

$\max \beta$

s.t. $\quad \sum_{1}^{N} \lambda_{j} y^{j}-\beta y^{0} \geq y^{0}$

$$
\begin{aligned}
& \sum_{1}^{N} \lambda_{j} x^{j}+\beta x^{0} \leq x^{0} ; \\
& \sum_{1}^{N} \lambda_{j}=1 ; \\
& \lambda_{j} \geq 0(j=1,2, \ldots, N) ; \beta \text { unrestricted. }
\end{aligned}
$$


This is a straightforward LP problem and can be solved quite easily. The factor $\beta$ is the NerloveLuenberger measure of technical inefficiency of the firm. By implication, its efficiency equals (1- $\beta$ ).

\section{Debreu-Farrell and Nerlove-Luenberger Super-efficiency Measures}

The standard DEA models - both the CCR model for CRS and the BCC model for VRS - provide measures of technical efficiency of a firm relative to the others within the same sample. Firms that are found to be technically inefficient can be ranked in order of their measured levels of efficiency. Firms that are found to be efficient are, however, all ranked equally by this criterion. Andersen and Petersen (1993) suggest a criterion that permits one to rank order firms that all found to be at $100 \%$ technical efficiency by DEA. The underlying idea behind this criterion is quite simple. Consider the single-input, single-output case. Suppose that a firm with input-output $\left(x_{0}, y_{0}\right)$ has been found to be technically efficient in an output-oriented DEA problem. Obviously, if its output had been any larger than $y_{0}$ it would have remained efficient. But a small reduction in its output will not necessarily lower its technical efficiency rating from $100 \%$. In that sense, this firm may allow some deterioration in its performance without becoming inefficient. In other words, its observed output exceeds what is necessary for this firm to be considered efficient relative to other firms in the sample. In that case, the firm may be regarded as super-efficient. Naturally, between two firms both of which are technically efficient, the one with a greater room for reducing its output without becoming inefficient is, in a sense, more super-efficient than the other. For any individual firm $k$, the modified production possibility set can be constructed as

$$
T_{k}^{-}=\left\{(x, y): x \geq \sum_{\substack{j=1 \\ j \neq k}}^{N} \lambda_{j} x^{j} ; y \leq \sum_{\substack{j=1 \\ j \neq k}}^{N} \lambda_{j} y^{j} ; \sum_{\substack{j=1 \\ j \neq k}}^{N} \lambda_{j}=1 ;(j=1,2, \ldots, N ; j \neq k)\right\} .
$$

In the general case of $N$ firms with the observed input-output bundle $\left(x^{j}, y^{j}\right)$ for firm $j(=1,2, \ldots, N)$, for each technically efficient firm $k$, we solve the following DEA problem for measuring the usual DebreuFarrell super-efficiency of firm $k$ :

$$
\begin{aligned}
& \phi_{k}^{-}=\max \phi \\
& \text { s.t. } \sum_{j \neq k} \lambda_{j} y^{j} \geq \phi y^{k} ; \\
& \sum_{j \neq k} \lambda_{j} x^{j} \leq x^{k} ; \\
& \sum_{j \neq k} \lambda_{j}=1 ; \lambda_{j} \geq 0(j=1,2, . ., N ; j \neq k) .
\end{aligned}
$$


The output bundle $y_{k}^{-}=\phi_{k}^{-} y^{k}$ is what the firm $k$ needs to produce from the input bundle $x^{k}$ in order to remain (output-oriented) technically efficient relative to the other firms in the sample. Thus, $\frac{1}{\varphi_{k}^{-}}$is a measure of its super-efficiency. Two things may be noted. First, as noted before, if firm $k$ is found to be technically inefficient in a conventional BCC DEA model, its exclusion from the reference set has no impact on its measured efficiency level. Thus, its super-efficiency measure is the same as its standard efficiency measure. Second, if the firm $k$ is "extreme efficient" as defined by Charnes, Cooper, and Thrall (1994), $\varphi_{k}^{-}<1$ and its super-efficiency is greater than 1 . Hence, between two firms $i$ and $j$, both technically efficient by the standard measure, $j$ is ranked above $i$, if $\phi_{j}^{-}<\phi_{i}^{-}$.

The directional distance function for firm $k$ with reference to the modified production possibility set is

$$
\beta_{k}^{-}=\max \beta:\left((1+\beta) y^{k},(1-\beta) x^{k}\right) \in T_{k}^{-} .
$$

The relevant DEA model for computing the Nerlove-Luenberger super-efficiency of firm $k$ is:

$$
\begin{aligned}
& \max \beta \\
& \text { s.t. } \quad \sum_{\substack{j=1 \\
j \neq k}}^{N} \lambda_{j} y^{j}-\beta y^{k} \geq y^{k} \\
& \\
& \sum_{\substack{j=1 \\
j \neq k}}^{N} \lambda_{j} x^{j}+\beta x^{k} \leq x^{k} \\
& \sum_{\substack{j=1 \\
j \neq 1}}^{N} \lambda_{j}=1 ; \\
& \lambda_{j} \geq 0(j=1,2, \ldots, N ; j \neq k) ; \beta \text { unrestricted. }
\end{aligned}
$$

If firm $k$ is Nerlove-Luenberger super-efficient, $\beta_{k}^{-}<0$ implying that the output bundle of the firm has to be scaled down while its input bundle is scaled up in order to get an attainable input-output bundle in the modified production possibility set. Between two firms both Nerlove-Luenberger super-efficient, the one with a lower (i.e., more pronouncedly negative) value of $\beta$ is ranked higher in terms of super-efficiency.

\section{The Problem of Infeasibility in Super-efficiency Models}

It is apparent that this super-efficiency DEA problem in (6) is infeasible if all possible convex combinations of the input vectors of the remaining firms are weakly greater than $x^{k}$. A special case of this is 
one where any one of the element of the input bundle $x^{k}$ is strictly smaller than the corresponding element of the input bundles of all the other firms in the sample. ${ }^{2}$

Note, however, that in most cases this does not pose any problem in a VRS DEA model of Nerlove-Luenberger super-efficiency. By selecting a negative value of $\beta$ one can scale down the output bundle and scale up the input bundle of the firm under evaluation. Typically a negative optimal value of $\beta$ yields a projection of $\left(x^{k}, y^{k}\right)$ on to a non-negative input-output bundle that lies on the frontier of the modified production possibility set $T_{k}^{-}$. There are two exceptions, however.

First, if

$$
\begin{aligned}
& 2 x^{k}<\sum_{\substack{j=1 \\
j \neq k}}^{N} \lambda_{j} x^{j} \text { for all } \lambda_{j} \text { s satisfying } \\
& \sum_{\substack{j=1 \\
j \neq k}}^{N} \lambda_{j}=1 ; \lambda_{j} \geq 0(j=1,2, \ldots, N ; j \neq k),
\end{aligned}
$$

one must set $\beta$ at a value lower than -1 (i.e., more than double the input bundle $x^{k}$ ). But in the process the output bundle is rendered negative. Although, the relative magnitude of the optimal $\beta$, whether positive or negative, remains a valid criterion for ranking firms in terms of their super-efficiency, a negative output bundle at the efficient projection of $\left(x^{k}, y^{k}\right)$ creates a conceptual problem.

The other case is one where at least one element of the input bundle of firm $k$ is 0 and all other firms in the sample use strictly positive quantities of that input. For every $\beta$ (whether positive negative, or zero) the corresponding element of the bundle $(1-\beta) x^{k}$ remains zero and the relevant input constraint in the problem (7) remains infeasible.

For reasons explained below, the method proposed by LR, by contrast, always yields a feasible solution of the relevant LP problem. This is true even when the firm under review is the only one in the sample with a 0 input of any factor. This, however, is a mere artifact of the way the model is constructed and the resulting super-efficiency measure has no economic meaning. Moreover, even though it does provide a super-efficiency measure of each firm, the problematic firms are all tied at the top.

\section{The Lovell-Rouse Method:}

Consider again the output-oriented DEA problem for Debreu-Farrell super-efficiency in (6) above.

Now replace the output bundle of firm $k$ by $\bar{y}^{k}=\delta y^{k}$ where $0<\delta<1$ is a scale factor that is determined in light of the sample data. Next solve the following conventional output-oriented BCC DEA problem for the surrogate of firm $k$ with input-output bundles $\left(x^{k}, \bar{y}^{k}\right)$ :

\footnotetext{
${ }^{2}$ Analogous conditions for infeasibility of input-oriented BCC super-efficiency models can be found in the relevant literature (e.g., Harker and Xue (2002)).
} 


$$
\begin{array}{ll} 
& \bar{\phi}_{k}=\max \phi \\
\text { s.t. } & \sum_{j \neq k} \lambda_{j} y^{j}+\lambda_{k} \bar{y}^{k} \geq \phi \bar{y}^{k} ; \\
& \sum_{j \neq k} \lambda_{j} x^{j}+\lambda_{k} x^{k} \leq x^{k} ; \\
\sum_{j \neq k} \lambda_{j}+\lambda_{k}=1 ; \lambda_{j} \geq 0(j=1,2, . ., N) ; \phi \text { unrestricted. }
\end{array}
$$

In most situations, by selecting an appropriately small value of $\delta$ one can ensure that $\left(x^{k}, \bar{y}^{k}\right)$ is an inefficient input-output combination and, hence, $\lambda_{k}$ equals 0 at the optimal solution of (9). Thus, $\bar{\phi}$ provides a measure of the (inverse) of the output-oriented Debreu-Farrell super-efficiency of a firm producing the output bundle $\bar{y}^{k}$ from the input bundle $x^{k}$. Hence, a measure of the corresponding outputoriented super-efficiency of the observed input-output pair is

$$
\tau_{O}=\frac{\delta}{\bar{\phi}}
$$

Note that the only time $\lambda_{k}$ will be strictly positive at the optimal solution of (9) is when all convex combinations of the input vectors of the other firms in the sample are weakly greater than the observed input bundle of firm $k$. In this case, $\bar{\phi}$ equals unity and

$$
\tau_{O}=\delta
$$

But this is the case where the input-attainability assumption fails for the output bundle $y^{k}$ with reference to the modified production possibility set constructed from the input-output bundles of the sample firms other than $k$ and the conventional DEA problem shown in (6) would be infeasible. As noted by LR, the optimal solution for both the standard output-oriented BCC DEA and the modified super-efficiency DEA for firm $k$ would be unity and, as defined by Harker and Xue (2002), firm $k$ is strongly super-efficient in this case. For the comparable input-oriented problem we define the revised input vector $\bar{x}^{k}=\alpha x^{k}$ where $\alpha>1$ is an arbitrary scale factor. Next we solve the DEA problem:

$$
\begin{aligned}
\bar{\theta}_{k}=\min \theta & \\
\text { s.t. } & \sum_{j \neq k} \lambda_{j} y^{j}+\lambda_{k} y^{k} \geq y^{k} \\
& \sum_{j \neq k} \lambda_{j} x^{j}+\lambda_{k} \bar{x}^{k} \leq \theta \bar{x}^{k} ; \\
& \sum_{j \neq k} \lambda_{j}+\lambda_{k}=1 ; \lambda_{j} \geq 0(j=1,2, . ., N) ; \theta \text { unrestricted. }
\end{aligned}
$$


The corresponding input-oriented super-efficiency measure is

$$
\tau_{I}=\bar{\theta} \alpha
$$

LR suggest selecting

$$
\alpha=\max i\left\{\max x_{i j} / \min x_{i j}\right\}+1
$$

for the input-oriented model. Similarly, for the output-oriented approach, one may set

$$
\delta=\left[\max r\left\{\max y_{r j} / \min y_{r j}\right\}+1\right]^{-1} .
$$

An advantage of this procedure is that because the bundle $\left(x^{k}, \bar{y}^{k}\right)$ is in the reference set of the problem in (9),a solution with $\bar{\phi}$ equal to unity will always be feasible for this problem. This is true, even when firm $k$ is the only firm with a 0 level of any one input. Similarly, $\left(\bar{x}^{k}, y^{k}\right)$ is in the reference set and $\bar{\theta}$ equal to unity is always a feasible solution for the problem in (11). By contrast, as noted earlier, the LuenbergerNerlove super-efficiency problem in (8) will not have a feasible solution in such cases.

There are two problems with this approach, however. First, whenever for any firm $\bar{\phi}$ equals unity, its output-oriented Debreu-Shephard super-efficiency equals $\frac{1}{\delta}$. Similarly, whenever $\bar{\theta}$ equals unity, the corresponding input-oriented super-efficiency equals $\alpha$. Thus, this approach fails to provide a ranking of these strongly super-efficient firms. Secondly, and just as important, the super-efficiency measure is entirely determined by the arbitrarily chosen value of $\delta$ or $\alpha$ and has no meaningful economic interpretation.

\section{A Comparison of the Two Approaches:}

We use the following data from Seiford and Zhu (19978; Table 7) to illustrate the difference between the modified super-efficiency model due to RL and the Nerlove-Luenberger super-efficiency model proposed here. 
Table 1. Hypothetical Input-output Data for 10 Firms

$\begin{array}{lrrrrr}\text { Name } & x 1 & x 2 & x 3 & y 1 & y 2 \\ & & & & 5008 & 5303 \\ \text { D1 } & 182 & 237 & 468 & 1857 & 2336 \\ \text { D2 } & 74 & 82 & 148 & 4001 \\ \text { D3 } & 160 & 195 & 400 & 4041 & 5001 \\ \text { D4 } & 183 & 150 & 339 & 2779 & 2418 \\ \text { D5 } & 133 & 155 & 329 & 3506 & 3602 \\ \text { D6 } & 106 & 120 & 138 & 1306 & 956 \\ \text { D7 } & 109 & 110 & 188 & 1515 & 2282 \\ \text { D8 } & 240 & 243 & 806 & 7763 & 9601 \\ \text { D9 } & 276 & 188 & 574 & 4577 & 6493 \\ \text { D10 } & 191 & 117 & 466 & 3322 & 4233\end{array}$

Source: Seiford and Zhu (1998; Table 7)

The various super-efficiency measures for the firms shown in Table 1 are reported below in Table 2.

Table 2. Alternative Measures of Super Efficiency name Super- $E_{1} \quad$ Super- $E_{O} \quad$ Msuper $_{1} \quad$ MSuper- $_{O} \quad N L$

\begin{tabular}{lcrrrr} 
D1 & 1.0626 & 1.0551 & 1.0626 & 1.0551 & 1.02847 \\
D2 & \multicolumn{1}{c}{1.5277 infeasible } & 1.5277 & 11 & 1.44299 \\
D3 & 0.9765 & 0.9796 & 0.9765 & 0.9796 & 0.98894 \\
D4 & 0.7354 & 0.7617 & 0.7354 & 0.7617 & 0.85662 \\
D5 & 0.9752 & 0.9777 & 0.9752 & 0.9777 & 0.98812 \\
D6 & 1.0725 infeasible & 1.0725 & 11 & 1.07246 \\
D7 & 0.7852 & 0.8216 & 0.7852 & 0.8216 & 0.88626 \\
D8 & infeasible & 1.6223 & 6 & 1.6223 & 1.38359 \\
D9 & 0.9246 & 0.9224 & 0.9246 & 0.9224 & 0.95808 \\
D10 & 1.0642 & 1.0811 & 1.0642 & 1.0811 & 1.03339
\end{tabular}

The column identified as Super- $\mathrm{E}_{\mathrm{I}}$ shows the input-oriented Debreu-Shephard super-efficiency measures of the individual firms. Firms D1, D2, D6, and D10 are super-efficient whereas firm D8 without a feasible solution for the conventional input-oriented super-efficiency DEA problem is strongly super-efficient. MSuper- $E_{I}$ shows the modified input-oriented super-efficiency obtained from the solution of problem (11). For this problem, we set $\alpha$ equal to 6 . Note that, for the strong super-efficient firm D8, this measure equals 6. Super- $E_{O}$ shows the conventional super-efficiency measures of the same 10 firms. Three firms, D1, D8, and D10 are super-efficient while firms D2 and D6 without feasible solutions for the conventional outputoriented super-efficiency DEA problem are strongly efficient. Both of these firms are assigned an outputoriented super-efficiency value 11 (equal to the inverse of the value chosen for $\delta$ ) in the column showing the modified super-efficiency $\left(M S u p e r-E_{O}\right)$. Finally, NL shows the levels of Nerlove-Luenberger super- 
efficiency $(1-\beta)$ for the different firms. Note that for the super-efficient firms, the optimal value of $\beta$ is negative leading to measured super-efficiency levels exceeding unity. Unlike the modified super-efficiency measures (either input or output-oriented), however, the NL measures are not identical for the strongly super-efficient firms. For example, firms D2 and D6 cannot be ranked in order of output-oriented superefficiency although D2 ranks way above D6 in terms of input-oriented super-efficiency. The NerloveLuenberger directional super-efficiency measure clearly ranks D2 higher than D6.

The more important point to note is that the unlike the RL modified super-efficiency measures, the NL directional super-efficiency measures can be easily interpreted. For example, firm D2 could increase all of its inputs and at the same time reduce all of its outputs by about $44.3 \%$ without becoming inefficient relative to the other firms in the sample. Firm D6 could similarly scale up its input bundle and scale down its output bundle by $7 \%$ and still remain efficient. Their, modified output-oriented super-efficiency rating of $1100 \%$ does not mean that they actually produce 11 times what would be minimally required for them to retain an output-oriented technical efficiency of $100 \%$. A different choice of the scale factor $\beta$ would yield a different super-efficiency rating.

\section{An Application to Airlines Data:}

This example considers the performance of 28 international airlines from North America, Europe, and Asia-Australia during the year 1990. The data set is taken from Coelli, Grifell-Tatje, and Perelman (2002, Table 1). Each firm produces two outputs: (a) passenger-kilometers flown (PASS) and (b) freight tonne-kilometers flown $(C A R G O)$. Inputs used are: (i) number of employees ( $L A B)$, (ii) fuel measured in millions of gallons) (FUEL), (iii) other inputs (millions of U.S. dollar equivalent) consisting of operating and maintenance expenses excluding labor and fuel expenses, (MATERIAL) and (iv) capital (sum of the maximum take-off weights of all aircrafts flown multiplied by the number of days flown) (CAP). The input-output data set is shown in Table 3. Various super-efficiency measures are reported for these firms in

Table 4. For the modified input-oriented problem we set $\alpha$ equal to 39.4. The optimal value of $\bar{\theta}$ equals unity for 3 airlines (LUFTHANSA, AMERICAN, and UNITED). Each of these strongly super-efficient firms is assigned a LR input-oriented super-efficiency score of 39.4. From the entries in the column identified as "LR-inp", we find that 12 other firms (JAL, SAUDIA, SINGAPORE, AUSTRIAN, FINNAIR, SWISSAIR, PORTUGAL, NORTHWEST, PANAM, and TWA) are also super-efficient. Note that while these 13 firms can be ranked in order of super-efficiency, the earlier 3 are all tied at 39.4. For the output-oriented LR 
Table 3. Input-Output Data from Selected Airlines for the year 1990

$\begin{array}{rlrrrrrr}\text { Obs } & \text { NAME } & \text { PASS } & \text { CARGO } & \text { LAB } & \text { FUEL } & \text { MATL } & \text { CAP } \\ 1 & \text { NIPPON } & 35261 & 614 & 12222 & 860 & 2008 & 6074 \\ 2 & \text { CATHAY } & 23388 & 1580 & 12214 & 456 & 1492 & 4174 \\ 3 & \text { GARUDA } & 14074 & 539 & 10428 & 304 & 3171 & 3305 \\ 4 & \text { JAL } & 57290 & 3781 & 21430 & 1351 & 2536 & 17932 \\ 5 & \text { MALAYSIA } & 12891 & 599 & 15156 & 279 & 1246 & 2258 \\ 6 & \text { QUANTAS } & 28991 & 1330 & 17997 & 393 & 1474 & 4784 \\ 7 & \text { SAUDIA } & 18969 & 760 & 24708 & 235 & 806 & 6819 \\ 8 & \text { IINGAPORE } & 32404 & 1902 & 10864 & 523 & 1512 & 4479 \\ 9 & \text { AUSTRIA } & 2943 & 65 & 4067 & 62 & 241 & 587 \\ 10 & \text { BRITISH } & 67364 & 2618 & 51802 & 1294 & 4276 & 12161 \\ 11 & \text { FINNAIR } & 9925 & 157 & 8630 & 185 & 303 & 1482 \\ 12 & \text { IBERIA } & 23312 & 845 & 30140 & 499 & 1238 & 3771 \\ 13 & \text { LUFTHANSA } & 50989 & 5346 & 45514 & 1078 & 3314 & 9004 \\ 14 & \text { SAS } & 20799 & 619 & 22180 & 377 & 1234 & 3119 \\ 15 & \text { SWISSAIR } & 20092 & 1375 & 19985 & 392 & 964 & 2929 \\ 16 & \text { PORTUGAL } & 8961 & 234 & 10520 & 121 & 831 & 1117 \\ 17 & \text { AIR CANADA } & 27676 & 998 & 22766 & 626 & 1197 & 4829 \\ 18 & \text { AM. WEST } & 18378 & 169 & 11914 & 309 & 611 & 2124 \\ 19 & \text { AMERICAN } & 133796 & 1838 & 80627 & 2381 & 5149 & 18624 \\ 20 & \text { CANADIAN } & 24372 & 625 & 16613 & 513 & 1051 & 3358 \\ 21 & \text { CONTINENTAL } & 69050 & 1090 & 35661 & 1285 & 2835 & 9960 \\ 22 & \text { DELTA } & 96540 & 1300 & 61675 & 1997 & 3972 & 14063 \\ 23 & \text { EASTERN } & 29050 & 245 & 21350 & 580 & 1498 & 4459 \\ 24 & \text { NORTHWEST } & 85744 & 2513 & 42989 & 1762 & 3678 & 13698 \\ 25 & \text { PANAM } & 54054 & 1382 & 28638 & 991 & 2193 & 7131 \\ 26 & \text { TWA } & 62345 & 1119 & 35783 & 1118 & 2389 & 8704 \\ 27 & \text { UNITED } & 131905 & 2326 & 73902 & 2246 & 5678 & 18204 \\ 28 & \text { USAIR } & 59001 & 392 & 53557 & 1252 & 3030 & 8952\end{array}$

Source: Coelli, Griffel-Tatje, and Perelman (2002), Table 1. 


\begin{tabular}{|c|c|c|c|c|c|c|c|}
\hline कb & NAME & & LR-inp & & LR-out & beta & NL \\
\hline 1 & NIPPON & 0.0251 & 0.9888 & 83.917 & 0.993 & 0.00431 & 0.99569 \\
\hline 2 & CATHAY & 0.02337 & 0.9209 & 91.977 & 0.906 & 0.04486 & 0.95514 \\
\hline & GARUDA & 0.01883 & 0.7419 & 117.943 & 0.7066 & 0.15919 & 0.84081 \\
\hline 3 & & & & & & & \\
\hline 4 & JAL & 0.04432 & 1.7463 & 60.028 & 1.3882 & -0.20343 & 1.20343 \\
\hline 5 & MALAYSIA & 0.01965 & 0.7741 & 109.681 & 0.7598 & 0.13417 & 0.86583 \\
\hline 6 & QUANTAS & 0.02876 & 1.133 & 74.184 & 1.1233 & -0.06009 & 1.06009 \\
\hline 7 & SAUDIA & 0.02954 & 1.1638 & 70.362 & 1.1844 & -0.07982 & 1.07982 \\
\hline 8 & SINGAPORE & 0.03692 & 1.4546 & 56.174 & 1.4835 & -0.17072 & 1.17072 \\
\hline 9 & AUSTRIAN & 0.0617 & 2.4309 & 1 & 83.3333 & -1.4309 & 2.4309 \\
\hline 10 & BRITISH AIR & 0.02263 & 0.8915 & 91.925 & 0.9065 & 0.05287 & 0.94713 \\
\hline 11 & FINNAIR & 0.03519 & 1.3865 & 46.007 & 1.8113 & -0.20747 & 1.20747 \\
\hline 12 & IBERIA & 0.02008 & 0.7912 & 103.563 & 0.8047 & 0.11307 & 0.88693 \\
\hline 13 & LUFTHANSA & 1 & 39.4 & 39.5 & 2.1097 & -0.42583 & 1.42583 \\
\hline 14 & SAS & 0.02218 & 0.874 & 94.455 & 0.8823 & 0.06481 & 0.93519 \\
\hline 15 & SWISSAIR & 0.02763 & 1.0885 & 75.567 & 1.1028 & -0.04539 & 1.04539 \\
\hline 16 & PORTUGAL & 0.03115 & 1.2275 & 65.33 & 1.2756 & -0.11081 & 1.11081 \\
\hline 17 & $\begin{array}{r}\text { AIR } \\
\text { CANADA }\end{array}$ & 0.02348 & 0.9252 & 89.583 & 0.9302 & 0.03745 & 0.96255 \\
\hline 18 & $\begin{array}{l}\text { AMER } \\
\text { WEST }\end{array}$ & 0.03031 & 1.1943 & 68.972 & 1.2082 & -0.09132 & 1.09132 \\
\hline 19 & AMERICAN & 1 & 39.4 & 75.325 & 1.1063 & -0.05345 & 1.05345 \\
\hline 20 & CANADIAN & 0.023 & 0.9061 & 91.155 & 0.9142 & 0.04693 & 0.95307 \\
\hline 21 & $\begin{array}{r}\text { CONTINENT } \\
\text { AL }\end{array}$ & 0.02542 & 1.0015 & 83.22 & 1.0014 & -0.00071 & 1.00071 \\
\hline 22 & DELTA & 0.02394 & 0.9433 & 88.165 & 0.9452 & 0.02867 & 0.97133 \\
\hline 23 & EASTERN & 0.02118 & 0.8344 & 98.992 & 0.8418 & 0.08802 & 0.91198 \\
\hline 24 & $\begin{array}{r}\text { NORTHWES } \\
T\end{array}$ & 0.02582 & 1.0175 & 82.134 & 1.0146 & -0.00789 & 1.00789 \\
\hline 25 & PANAM & 0.02612 & 1.029 & 81.124 & 1.0272 & -0.01384 & 1.01384 \\
\hline 26 & TWA & 0.02561 & 1.0088 & 82.618 & 1.0087 & -0.00436 & 1.00436 \\
\hline 27 & UNITED & 1 & 39.4 & 77.882 & 1.07 & -0.05154 & 1.05154 \\
\hline 28 & USAIR & 0.02221 & 0.8752 & 94.429 & 0.8825 & 0.06442 & 0.93558 \\
\hline
\end{tabular}


problem, we set $\delta$ equal to 0.012 . This time, only one airline (AUSTRIAN) was strongly super-efficient and was assigned an LR super-efficiency score of 83.3333. Of the rest, 15 airlines (JAL, QUANTAS, SAUDIA, SINGAPORE, FINNAIR, LUFTHANSA, SWISSAIR, PORTUGAL, AMER WEST, AMERICAN, CONTINENTAL, NORTHWEST $<P A N A M$, TWA, and UNITED) were super-efficient. The modified superefficiency scores are reported in the column "LR-out". Finally, the column "beta" reports the directional distance function values and the Nerlove-Luenberger super-efficiency measures are shown in the column "NL". For one airline (AUSTRIAN) the directional distance function $(\beta)$ is lower than -1 . As a result, at the projection of the observed input-output bundle onto the modified frontier, the output bundle would be negative. This clearly, is problematic. For the other airlines, however, the results are quite sensible and can be easily interpreted. The NL super-efficiency of 16 firms permits a completed ordering of all of these firms. Note that while the RL input-oriented measure results in a tie for LUFTHANSA, AMERICAN, and UNITED, the NL measure ranks LUFTHANSA way above the other two firms while AMERICAN barely dominates UNITED. It is interesting to note that the LR-output oriented super-efficiency would generate the same ranking of these firms. The fact that the directional distance function combines features of both an input-oriented and an output-oriented model, generally leads to a more complete ranking of the observations than either of the oriented models. An added advantage of this approach is that the NL superefficiency measure is unique and does not depend on any arbitrary choice of a scaling parameter.

\section{Conclusion:}

A radial DEA models of super-efficiency has no feasible solution if Shephard's input (output) attainability assumption is violated. The method proposed by LR ensures a feasible solution of the appropriately modified problem. However, even under this procedure firms that are strongly super-efficient are all tied at the maximum score. Moreover, the super-efficiency score of these firms depends on the arbitrary choice of the scaling parameter and cannot be interpreted. By contrast, the NL super-efficiency scores obtained from the direction distance function are unique, easily interpreted, and yield a complete ranking of firms in the sample. There are two limitations of this approach, however. First, no feasible solution is obtained if the firm under evaluation has any input at the zero level. Second, when the NL super-efficiency score exceeds 2 , the projected point in the input-output space involves negative output quantities. 


\section{References:}

Andersen, P. and N.C. Petersen (1993) "A Procedure for Ranking Efficient Units in Data Envelopment Analysis”, Management Science,39, 1261-64.

Chambers, R.G., Y. Chung, and R. Färe (1996) Benefit and Distance Functions”, Journal of Economic Theory, 70 (August 1996), 407-19.

Chavas, J.P. and T.L. Cox(1999) "A Generalized Distance Function and the Analysis of Production Efficiency’; Southern Economic Journal, 66(2), 294-318.

Coelli, T., E. Griffel Tatje, and S. Perelman (2002) "Capacity Utilization and Profitability: A Decomposition of Short-run Profit Efficiency"; International Journal of Production Economics, $79,261-278$.

Dulá, J.H. and B.L. Hickman (1997) "Effects of Excluding the Column Being Scored from the DEA Envelopment LP Technology Matrix"; Journal of the Operational Research Society, 48, 10011012.

Lovell, C.A.K. and A.P.B. Rouse (2003) "Equivalent Standard DEA Models to Provide Super-Efficiency Scores"; Journal of the Operational Research Society, 54(1), 101-108.

Luenberger, D.G. (1992) “Benefit Functions and Duality”, Journal of Mathematical Economics, 21, 115-145.

Seiford, L.R. and J. Zhu (1999) "Infeasibility of Super-efficiency Data Envelopment Analysis Models"; INFOR 37, 2, 174-187.

Shephard, R.W. (1970) Theory of Cost and Production Functions (Princeton University Press).

Thrall, R.M. (1996) "Duality, classification and slacks in DEA";Annals of Operations Research; 66, 109-38. 